\title{
Mechanical circulatory assistance: A growing and expanding field in cardiac surgery
}

\author{
Cipriano Abad, MD
}

\author{
From the Department of Cardiovascular Surgery, Hospital Universitario de GC Dr Negrin, Las Palmas de Gran \\ Canaria, Spain. \\ Disclosures: Author has nothing to disclose with regard to commercial support. \\ Received for publication Oct 4, 2015; accepted for publication Oct 5, 2015; available ahead of print Oct 30, 2015. \\ Address for reprints: Cipriano Abad, MD, Department of Cardiovascular Surgery, Hospital Universitario de GC \\ Dr Negrin, Barranco de la Ballena s/n, 35020 Las Palmas de Gran Canaria, Spain (E-mail: cprnabad2@gmail. \\ com). \\ J Thorac Cardiovasc Surg 2016;151:e9-10 \\ $0022-5223 / \$ 36.00$ \\ Copyright (c) 2016 by The American Association for Thoracic Surgery \\ http://dx.doi.org/10.1016/j.jtcvs.2015.10.013
}

I read with interest the article of Khalpey and colleagues ${ }^{1}$ appearing in this issue of the Journal. They present a clinical work of 3 cases treated with a novel technique for minimally invasive off-pump biventricular assist device implantation. Khalpey and colleagues ${ }^{1}$ report a nice, innovative technique that is less invasive, with insertion without sternotomy and need for cardiopulmonary bypass. The implant technique for the left ventricular assist device (LVAD) was through a left minithoracotomy; the apex of the left ventricle was exposed, and a $28 \mathrm{~F}$ Protek Duo cannula (CardiacAssist, Inc, Pittsburgh, Pa) was inserted in the ascending aorta, with the inflow located in the left ventricle and the outflow in the aorta. The implantation of the right ventricular assist device was through the internal jugular vein; a 29F Protek cannula was inserted in the trunk of the pulmonary artery, with the inflow in the right atrium and the outflow in the pulmonary artery. Right and left ventricular supports were titrated at $3.5 \mathrm{~L} / \mathrm{min}$ and $4 \mathrm{~L} / \mathrm{min}$, respectively. The 2 first assisted patients did well; the third patient died during the postoperative period.

Since the first generation of mechanical circulatory assistance devices (MCADs), encompassing LVADs, right ventricular assist devices, and biventricular assist devices that used large systems of pulsatile flow (pneumatically or electrically driven), paracorporeal or intrathoracic location, through the latest generation of devices with continuous flow, which are smaller, safer, more biocompatible, and constructed with new materials and designs and with magnetically suspended levitated rotor technology, many advances, improvements, and better results have been achieved.

In the last 15 years, significant advancement and new relevant data have been reported. The Randomized Evaluation of Mechanical Assistance for the Treatment of Congestive Heart Failure (REMATCH) ${ }^{2}$ and postREMATCH $^{3}$ studies showed better survival in patients treated with the HeartMate I (Thoratech, Pleasanton, Calif) in comparison with pharmacologic treatment. The

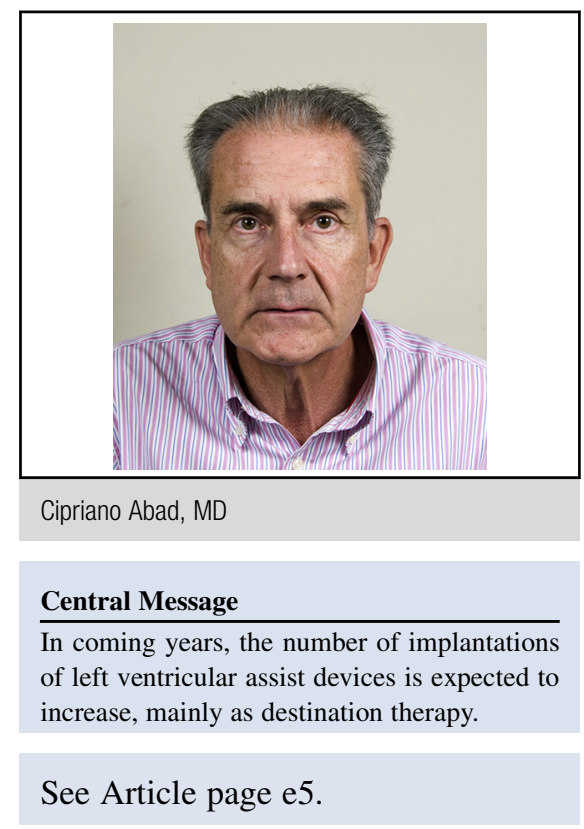

Investigation of Nontransplant-Eligible Patients Who Are Inotrope Dependent (INTREPID) ${ }^{4}$ study showed better 1-year survival in patients managed with the first generation Novacor LVAD (World Heart Corp, Salt Lake City, Utah) than the medical group (27\% vs $11 \%)$. In the HeartMate II Destination Therapy Trial, ${ }^{5}$ the 2-year survival was better in the group of patients treated with the second-generation HeartMate II than with the HeartMate VXE (58\% vs 24\%). In the Evaluation of the HeartWare Left Ventricular Assist Device for the Treatment of Advanced Heart Failure (ADVANCE) trial, ${ }^{6}$ with the HeartWare HVAD as a bridge to transplantation the 12-month survival was $86 \%$.

The newer generation of extracorporeal life support systems using continuous flow have been proven to be more efficient, durable, and effective. Whereas MCADs were once approved and used only as a bridge to heart transplant, today they are also indicated as a bridge to recovery, as a bridge to decision, as a bridge to candidacy, and even as permanent or destination therapy.

Although cardiac transplantation is considerer the best option for selected patients in end-stage heart failure, the worldwide high prevalence and incidence of heart failure, older age of the population in developed countries, shortage of heart donors, and patient contraindications to transplantation are increasing the demand for MCADs. 
Patients with advanced and refractory heart failure or cardiogenic shock secondary to acute myocardial infarction, post-cardiopulmonary bypass or other cardiac conditions not responding to conventional medical therapy, catheter interventional cardiology treatments, or cardiac surgery should be considered for MCAD placement, as should patients in unstable condition awaiting heart transplantation and patients not amenable to transplantation. Despite new drugs, catheter interventional cardiology, cardiac resynchronization, implantable cardiac defibrillators, advanced pacing, modern medical therapies (stem cells, gene therapy), cardiac surgery, and transplantation, many patients with severe and advanced heart failure are potential candidates for MCADs.

Appropriate selection of the patient for MCAD is of paramount importance. Indication and proper identification of the patients can be a complex process requiring knowledge, expertise and experience. For patients in cardiogenic shock after cardiopulmonary bypass who cannot be weaned from extracorporeal circulation, an immediate decision must be taken by the surgeon. In other situations, the decision should be made by the heart team. The indications for MACD implantation can be seen in the guidelines of the American Heart Association ${ }^{7}$ and the guidelines of the International Society for Heart and Lung Transplantation. ${ }^{8}$

In the sixth Interagency for Mechanically Assisted Circulatory Support (INTERMACS) report, published by Kirklin and colleagues, ${ }^{9}$ among 10,542 LVADs implanted between June 2008 and December 2013, 9112 were continuous-flow devices. The proportion of patients receiving a durable device as destination therapy was $14.7 \%$ in the period from 2006 to 2007 and increased to $41.6 \%$ in the period from 2011 to 2013. Actuarial survivals at 1 and 2 years with continuous flow pumps were $80 \%$ and $70 \%$, respectively.

LVADs are being more frequently used as a viable option in different settings of heart failure, although their use is still limited. Because of recent publications regarding data on survival ${ }^{9}$ and demonstration in the heart of MACD carriers relevant information regarding reduction in ventricular hypertrophy, reverse remodeling, and reversed inflammatory changes,${ }^{10}$ their use is expected to increase.
The number of implants of LVADs and long-acting pumps as a destination therapy is clearly presumed to enlarge significantly.

Continuous evolution and innovation in device designs (new percutaneous insertion models; robotic assistance; novel short-action, medium-action, and long-action devices; total artificial hearts), more cost-effective and with fewer collateral side effects (lessened thrombosis, infections, bleeding complications, and heat production) is ongoing. New designs are in development and will continue to improve the quality of life of a larger segment of patients with advanced heart failure.

The publication of Khalpey and colleagues ${ }^{1}$ represents an interesting, valuable, and useful contribution to this field.

\section{References}

1. Khalpey ZI, Smith R, Echeverria A, Le Tran P, Kazui T. A novel minimally invasive off-pump biventricular assist device insertion technique. J Thorac Cardiovasc Surg. 2016;151:e5-7.

2. Rose EA, Gelijns AC, Moskowitz AJ, Heitjan DF, Stevenson LW, Demihitsky W, et al. Randomized evaluation of Mechanical Assistance for the Treatment of Congestive Heart Failure (REMATCH) Study group. Long-term mechanical assistance for end-stage heart failure. $N$ Eng J Med. 2001;345:1435-43.

3. Lietz K, Long JW, Kfour AG, Slaughter MS, Silver MA, Milano CA, et al. Outcomes of left ventricular assist device implantation destination therapy in the POSREMATCH era. Implications for patient selection. Circulation. 2007; 116:497-505.

4. Rogers JG, Butler J, Lansman SL, Gass A, Portner PM, Pasque MK, et al. Chronic mechanically circulatory support for inotrope-dependent heart failure patients who are not trasnaplant candidates: results of the INTREPID trial. J Am Coll Cardiol. 2008;135:1353-60.

5. Slaughter MS, Rogers JG, Milano CA, Russel SD, Conte JV, Feldman D, et al. Advanced heart failure treated with continuous-flow left ventricle assist device. N Eng J Med. 2009;36:2241-51.

6. Aaronson KD, Slaughter MS, Miller LW, Mc Gee EC, Cotts WG, Acker MA, et al. Use of an intrapericardial continuous centrifugal pump in patients awaiting heart transplantation. Circulation. 2012;125:3191-200.

7. Yancy CW, Jessup M, Bozcurt B, Butler J, Casey DE Jr, Drazner MH, et al; American College of Cardiology Foundation; American Heart Association Task Force on Practice Guidelines. 2013 ACCF/AHA guideline for the management of the heart failure: a report of the American College of Cardiology Foundation/American Heart Association Task Force on Practice Guidelines. J Am Coll Cardiol. 2013;62:e147-279.

8. Feldman D, Pamboukian SV, Teuteberg JJ, Birks E, Lietz K, Moore SA, et al; International Society for Heart and Lung Transplantation. The 2013 International Society of Heart and Lung Transplantation guidelines for mechanical circulatory support: executive summary. J Heart Lung Transplant. 2013;32:157-87.

9. Kirklin JD, Naftel DC, Pagani FD, Kormos RL, Stevenson LW, Blume RD, et al. Sixth INTERMACS annual report: a 10,000 patient database. J Heart Lung Transplant. 2014;33:555-64.

10. Braunwald E. The war against heart failure: the Lancet lecture. Lancet. 2015;385: 812-24. 